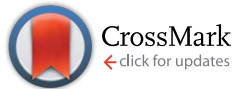

Cite this: Chem. Sci., 2015, 6, 666

Received 30th July 2014

Accepted 9th September 2014

DOI: $10.1039 / c 4 s c 02269 f$

www.rsc.org/chemicalscience

\title{
Laser-induced pinpoint hydrogen evolution from benzene and water using metal free single-walled carbon nanotubes with high quantum yields $\uparrow$
}

\author{
Kei Ohkubo, Naoki Kohno, Yusuke Yamada and Shunichi Fukuzumi*
}

\begin{abstract}
Metal-free photocatalytic hydrogen evolution occurred efficiently in benzene containing single-walled carbon nanotubes under laser irradiation at $532 \mathrm{~nm}$ with an extremely high turnover number of 2000000 and a high quantum yield of $130 \%$. The rate of hydrogen evolution increased with increasing laser intensity to exhibit a fourth power dependence, suggesting that hydrogen was evolved via fourphoton processes in which the coupling of two radical anions derived from benzene is the ratedetermining step and the benzene radical anion is produced by electron transfer from benzene to the doubly excited state of single-walled carbon nanotubes, which requires two photons. Polymerisation of benzene was induced by the photogenerated $\mathrm{C}_{6} \mathrm{H}_{6} \cdot{ }^{-}$, accompanied by hydrogen evolution, resulting in a leverage effect to increase the quantum yield of hydrogen evolution to well over the $25 \%$ expected for the four-photon process. Laser-induced hydrogen evolution also occurred in water containing singlewalled carbon nanotubes. In contrast to the case of benzene, water was not oxidized but hydrogen evolution from water was accompanied by the multi-oxidation of single-walled carbon nanotubes. The yield of hydrogen based on one mole of single-walled carbon nanotubes with $1.4 \mathrm{~nm}$ diameter and 1-5 $\mathrm{mm}$ length was determined to be $2700000 \%$, when oxidations of single-walled carbon nanotubes occurred to produce the polyhydroxylated product.
\end{abstract}

\section{Introduction}

Carbon nanomaterials have been widely studied for their potential applications as electrode materials for efficient energy conversion and storage. ${ }^{1-5}$ Metal-free nanostructured elemental carbons and carbon-based composites have proven to be attractive alternatives to conventional metal-based catalysts for several important chemical reactions such as dehydrogenation reactions of aromatic compounds, ${ }^{5-7}$ oxygenation $^{\mathbf{8}}$ and Friedel-Crafts reactions. ${ }^{\mathbf{9}, 10}$ However, these reactions were carried out under severe conditions to activate substrate molecules.

In particular, single-walled carbon nanotubes (SWCNTs) have been of great interest to researchers because of their unique structures and physical properties. ${ }^{11-17}$ SWCNTs have been proposed as advanced metal-catalyst supports for electrochemical catalysis. ${ }^{18-20}$ However, there are no reports that SWCNTs alone are used as photocatalysts under ambient

Department of Material and Life Science, Graduate School of Engineering, Osaka University, ALCA, Japan Science and Technology Agency (JST), Suita, Osaka 565-0871, Japan. E-mail: fukuzumi@chem.eng.osaka-u.ac.jp; Fax: +81 66879 7370; Tel: +81668797368

$\dagger$ Electronic supplementary information (ESI) available: GC and HPLC analyses for products characterisation (Fig. S1-S3 and S5), time course data of $\mathrm{H}_{2}$ evolution in various solvents (S4), IR (S6), TG (S7) and experimental details (S8). See DOI: 10.1039/c4sc02269f conditions due to their poor photochemical and excited properties.

Catalytic hydrogen $\left(\mathrm{H}_{2}\right)$ evolution systems have been extensively studied because hydrogen is a clean energy source for the future, which should reduce dependence on fossil fuels and emissions of greenhouse gases in the long term. ${ }^{21,22}$ In many cases, noble metals such as platinum and semiconductors have been used as photocatalysts. ${ }^{23-35}$ However, there are no reports on photocatalytic metal-free $\mathrm{H}_{2}$ evolution systems using pure carbon alone as a photocatalyst. $^{36}$

We report herein efficient $\mathrm{H}_{2}$ evolution from benzene and benzene derivatives using metal free SWCNTs alone as a photocatalyst under visible laser light irradiation (532 nm) at room temperature and atmospheric pressure with a high quantum yield of $130 \%$. Efficient laser-induced hydrogen evolution was also observed from water with SWCNTs. The reaction mechanisms of laser-induced $\mathrm{H}_{2}$ evolution from benzene and water with SWCNTs are clarified based on the oxidized products, deuterium kinetic isotope effects and the dependence of the rate of $\mathrm{H}_{2}$ evolution on the laser intensity. This is the first example of laser-induced $\mathrm{H}_{2}$ evolution with high quantum yields, paving a new way for pinpoint $\mathrm{H}_{2}$ production using a laser pulse, which may find various applications. 


\section{Results and discussion}

\section{Laser-induced photocatalytic hydrogen evolution from benzene with SWCNTs}

Laser pulse irradiation $(\lambda=532 \mathrm{~nm} ; 500 \mathrm{~mW} ; 10 \mathrm{~Hz})$ of a deaerated benzene solution $(2.5 \mathrm{~mL})$ containing dispersed metalfree SWCNTs $(0.15 \mathrm{mg})$ resulted in efficient hydrogen evolution. The amount of hydrogen evolved by laser irradiation for $2 \mathrm{~h}$ reached $100 \mu \mathrm{mol}(2.2 \mathrm{~mL})$. The quantum yield of hydrogen evolution was determined from the initial rate to be $34 \%$. When benzene was replaced by deuterated benzene $\left(\mathrm{C}_{6} \mathrm{D}_{6}\right)$, the deuterated hydrogen molecules such as $\mathrm{D}_{2}$ and $\mathrm{HD}$ were also evolved efficiently (see Fig. S1 in the ESI $\dagger$ ). The initial rate of hydrogen evolution was $21 \mu \mathrm{mol} \mathrm{h}{ }^{-1}$ with a $50: 1$ ratio for $\mathrm{D}_{2}$ and HD, respectively. The KIE (kinetic isotope effect) value was determined from the slopes in Fig. 1 to be 2.4. These results indicate that the hydrogen source is benzene. The products derived from the dehydrogenation of benzene were determined by GC-MS and HPLC analyses to be biphenyl, terphenyls, and terphenylene (see Fig. S2 and S3 in ESI $\dagger$ ). The stoichiometry required to produce $\mathrm{H}_{2}$ and biphenyl from benzene is given by eqn (1).

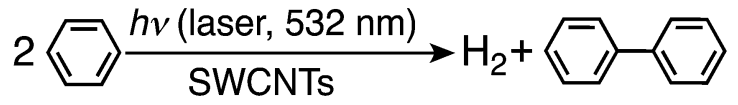

There is no evidence for the functionalisation of SWCNTs by benzene under photoirradiation, which was observed by TG analyses (Fig. 2) because no weight loss from the decomposition of functionalized molecules to SWCNTs was observed at low temperature. Thus, hydrogen was evolved via the condensation reaction of benzene in the photocatalytic reaction.

Hydrogen was also evolved in various aromatic solvents with electron withdrawing and donating substituent(s) (Fig. S4 in ESI $\dagger$ ). The amounts of $\mathrm{H}_{2}$ evolved are listed in Table 1 . The highest catalytic activity was obtained in benzene. The catalytic turnover number (TON) is roughly estimated as $(2.0 \pm 0.5) \times 10^{6}$ per SWCNT for $2 \mathrm{~h}$ irradiation,

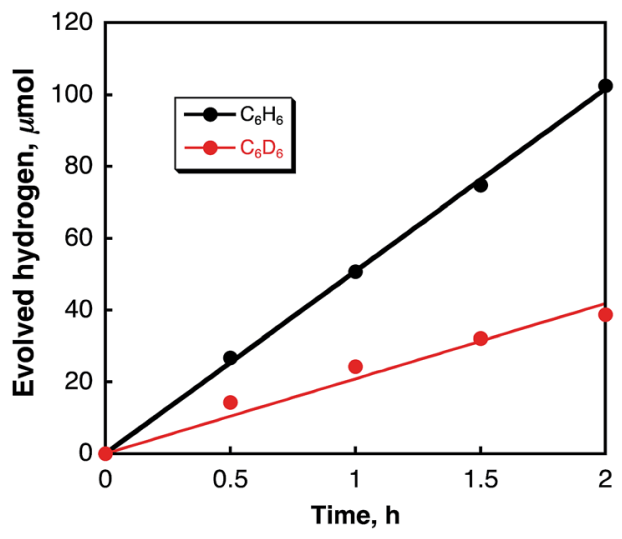

Fig. 1 Time courses of hydrogen evolution in deaerated $\mathrm{C}_{6} \mathrm{H}_{6}$ (black circles) and $\mathrm{C}_{6} \mathrm{D}_{6}$ (red circles) containing SWCNTs $\left(0.060 \mathrm{mg} \mathrm{mL}^{-1}\right.$ ) under laser irradiation at $532 \mathrm{~nm}(50 \mathrm{~mJ}$ per pulse).

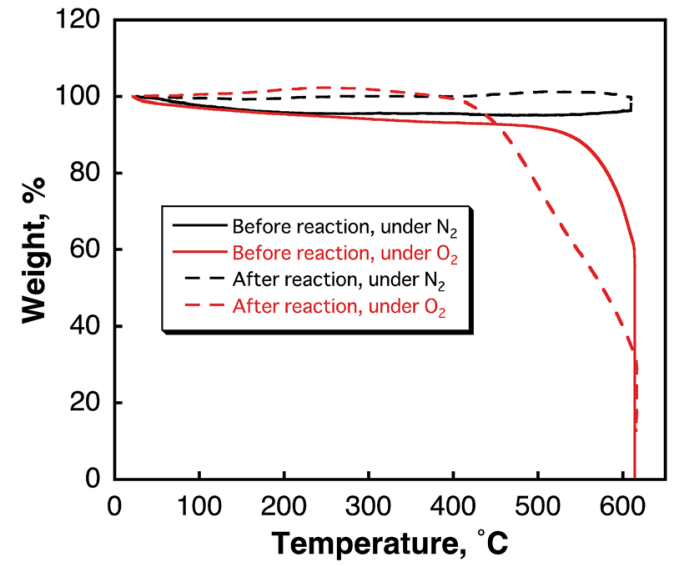

Fig. 2 TG curves of SWCNTs before and after laser light irradiation $\left(\mathrm{H}_{2}\right.$ evolution) in benzene observed under deaerated and aerated conditions.

calculated from the tube diameter and average length of the SWCNTs with a zig-zag structure used in this study. ${ }^{37}$ When benzene was replaced by benzene- $d_{6}$, the TON decreased to $(8.0 \pm 2.0) \times 10^{5}$ per SWCNT. This value agrees with the KIE of 2.4 determined from the initial rate of $\mathrm{H}_{2}$ evolution as shown in Fig. 1.

Transmission electron microscopy (TEM) measurements were performed to evaluate the transformation of SWCNTs before and after hydrogen evolution. The TEM images before photoirradiation (Fig. 3a and b) clearly exhibit tubular morphologies. There are no inorganic impurities in the commercially available and highly purified SWCNTs used in this study (see Experimental section). After hydrogen evolution, the tubular structure was partially changed to an agnail structure and small clusters. However, a tubular component still remains (Fig. 3c and d).

The dependence of the rate of $\mathrm{H}_{2}$ evolution on the laser intensity was examined using different laser power intensities at $532 \mathrm{~nm}\left(0-82 \mathrm{~mJ}\right.$ per pulse). The initial rates of $\mathrm{H}_{2}$ evolution are proportional to the fourth power of the laser intensity as shown in Fig. 4. This suggests that a bimolecular reaction of two-photon absorbed species may be involved in the photocatalytic hydrogen evolution.

Table 1 Amount of $\mathrm{H}_{2}$ evolved in various solvents after laser irradiation for $2 \mathrm{~h}$

\begin{tabular}{lc}
\hline Solvent & $\mathrm{H}_{2}$ evolved $^{a} \mu \mathrm{mol}$ \\
\hline Benzene & 100 \\
Mesitylene & 71 \\
Toluene & 66 \\
$p$-Xylene & 60 \\
Chlorobenzene & 54 \\
Benzonitrile & 39 \\
1,2-Dimethoxybenzene & 12
\end{tabular}

${ }^{a}$ Conditions: SWCNTs $(0.15 \mathrm{mg})$ dispersed in deaerated solvent $(2.5 \mathrm{~mL})$. Excited at $532 \mathrm{~nm}(50 \mathrm{~mJ}$ per pulse). 
(a)

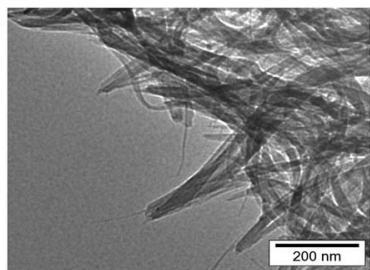

(c)
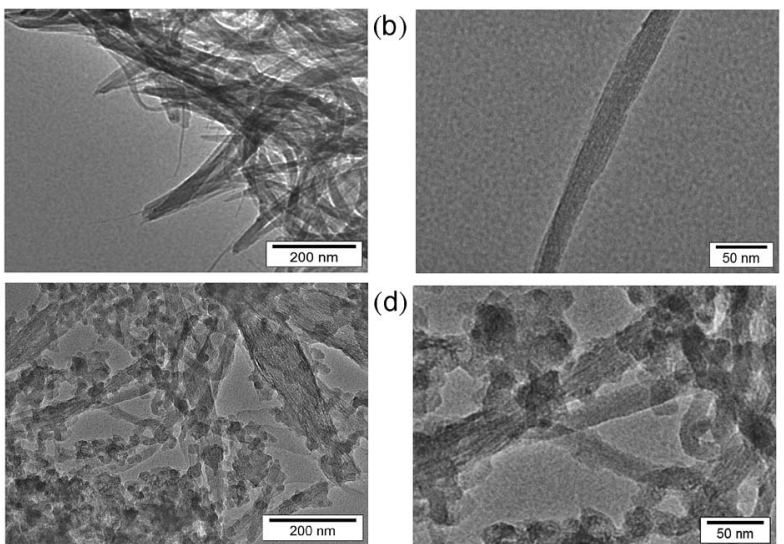

(d)

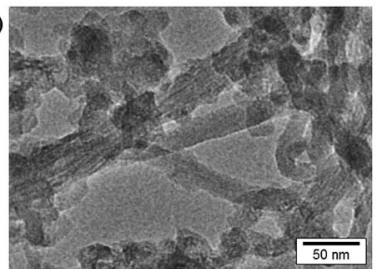

Fig. 3 TEM images of SWCNTs ( $a$ and $b$ ) before and ( $c$ and $d$ ) after laser photoirradiation $(50 \mathrm{~mJ}$ per pulse, $10 \mathrm{~Hz}$ ) for $2 \mathrm{~h}$ in deaerated benzene at $298 \mathrm{~K}$.
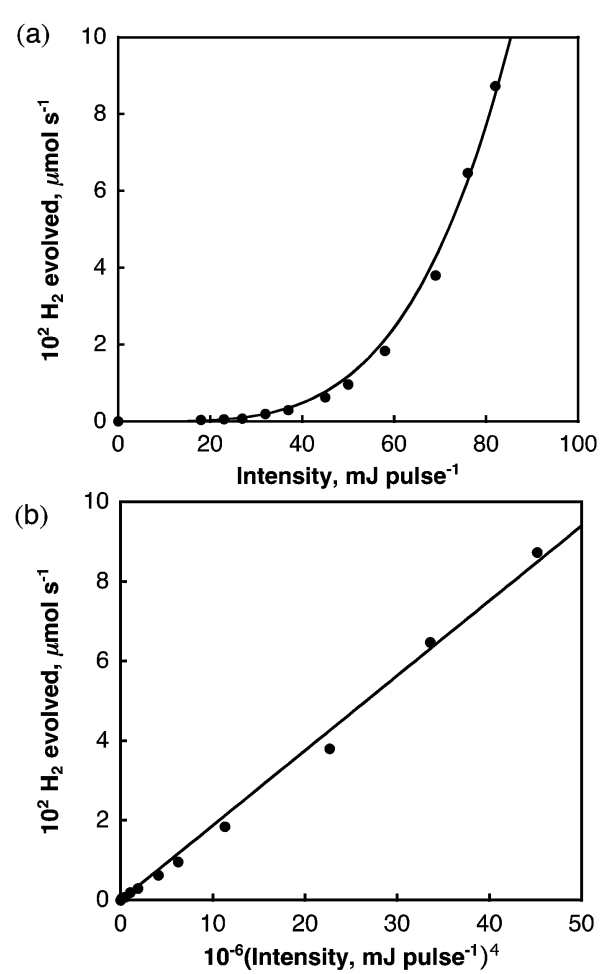

Fig. 4 (a) Plot of initial rate of $\mathrm{H}_{2}$ evolved in deaerated benzene vs. laser power intensity at $532 \mathrm{~nm}$; (b) plot of initial rate of $\mathrm{H}_{2}$ evolved vs. the fourth power of the laser intensity.

On the basis of the above-mentioned results, the plausible photocatalytic mechanism for hydrogen evolution in benzene is shown in Scheme 1. A SWCNT was excited by two photons to form a doubly excited SWCNT (SWCNT**). The SWCNT** can reduce benzene to produce the benzene radical anion $\left(\mathrm{C}_{6} \mathrm{H}_{6}{ }^{-}\right)$ and the one-electron oxidized SWCNT $\left(\mathrm{SWCNT}^{\cdot+}\right)$ with the rate constant $k_{\text {et1 }}$. Dimerisation of $\mathrm{C}_{6} \mathrm{H}_{6}{ }^{-}$occurs, accompanied by hydrogen evolution to produce the biphenyl dianion $\left[\left(\mathrm{C}_{6} \mathrm{H}_{5}\right)_{2}{ }^{2-}\right]$ with the rate constant $k_{\mathrm{H}}$. Such hydrogen evolution via the

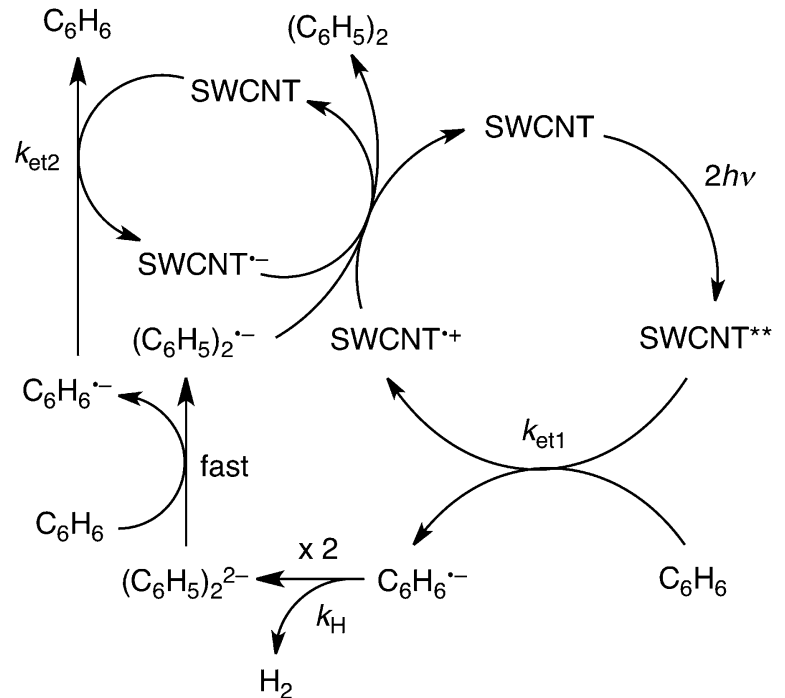

Scheme 1
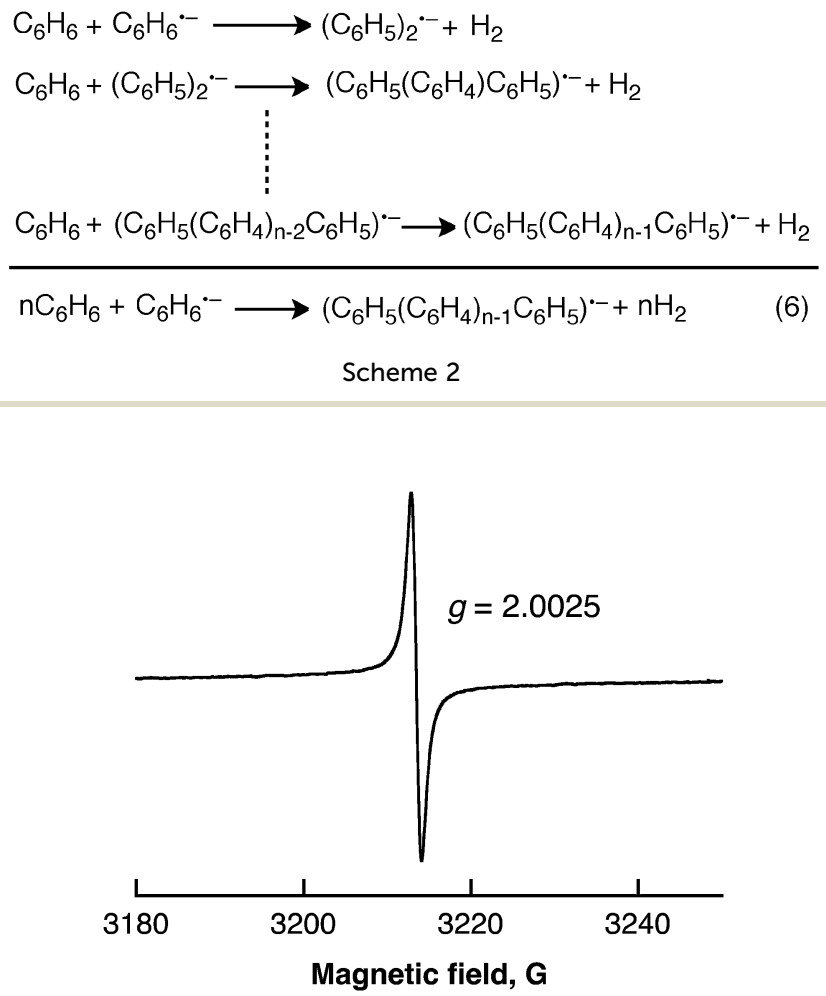

Fig. 5 ESR spectrum of benzene containing SWCNTs $\left(0.12 \mathrm{mg} \mathrm{mL}^{-1}\right)$ after laser pulse irradiation at $532 \mathrm{~nm}(40 \mathrm{~mJ}$ per pulse; $10 \mathrm{~Hz})$ for 10 $\min$ at $77 \mathrm{~K}$.

radical coupling of $\mathrm{C}_{6} \mathrm{H}_{6}{ }^{-}{ }^{-}$has previously been reported for the reduction of benzene with a cesium nano carbon catalyst. ${ }^{38}$ $\left(\mathrm{C}_{6} \mathrm{H}_{5}\right)_{2}{ }^{2-}$ can reduce benzene to produce $\mathrm{C}_{6} \mathrm{H}_{6}{ }^{-}$and the biphenyl radical anion $\left[\left(\mathrm{C}_{6} \mathrm{H}_{5}\right)_{2}{ }^{\cdot-}\right]$ in benzene. ${ }^{39}$ Back electron transfer from $\left(\mathrm{C}_{6} \mathrm{H}_{5}\right)_{2}{ }^{--}$to $\mathrm{SWCNT}^{\cdot+}$ results in the formation of biphenyl $\left[\left(\mathrm{C}_{6} \mathrm{H}_{5}\right)_{2}\right]$, accompanied by the regeneration of the SWCNT. On the other hand, $\mathrm{C}_{6} \mathrm{H}_{6}{ }^{--}$can reduce the SWCNT to 


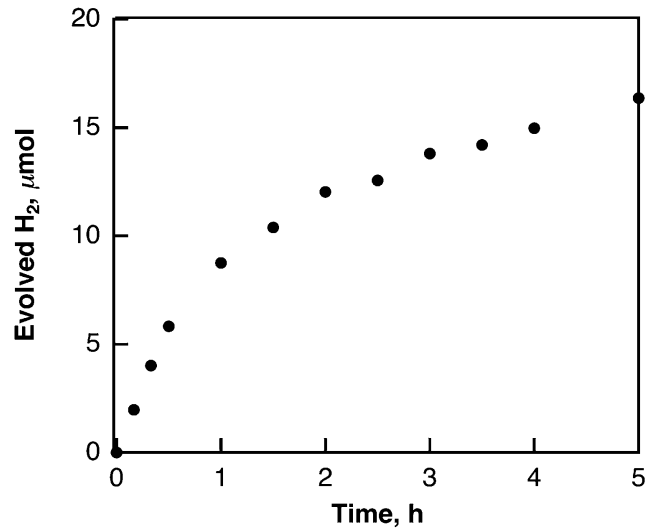

Fig. 6 Time course of hydrogen evolution in deaerated $\mathrm{H}_{2} \mathrm{O}$ containing SWCNTs $\left(0.80 \mathrm{mg} \mathrm{mL}^{-1}\right)$ under laser irradiation at $532 \mathrm{~nm}(60$ $\mathrm{mJ}$ per pulse; $10 \mathrm{~Hz}$ ).

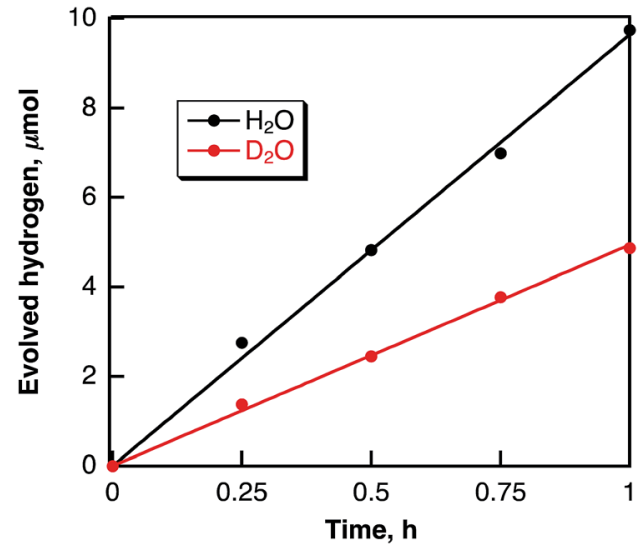

Fig. 7 Time courses of $\mathrm{H}_{2}$ and $\mathrm{D}_{2}$ evolution in deaerated $\mathrm{H}_{2} \mathrm{O}$ (black circles) and $\mathrm{D}_{2} \mathrm{O}$ (red circles), respectively, containing SWCNTs (0.80 $\mathrm{mg} \mathrm{mL}^{-1}$ ) under laser irradiation at $532 \mathrm{~nm}(60 \mathrm{~mJ}$ per pulse; $10 \mathrm{~Hz})$.

(a)

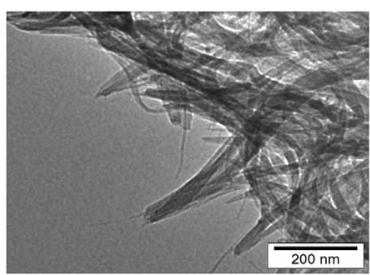

(c)
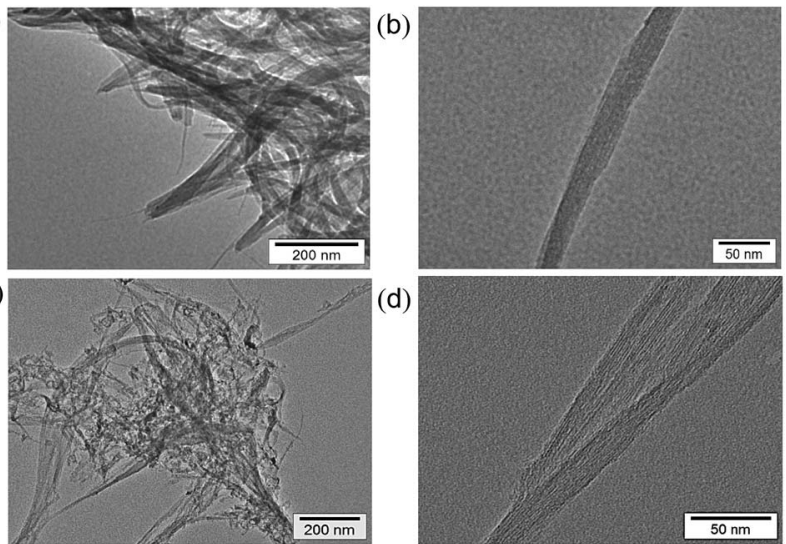

(d)

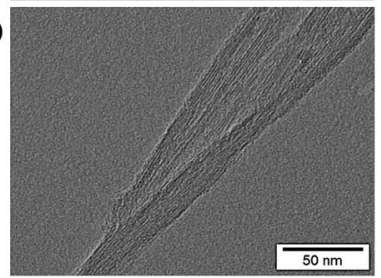

Fig. 8 TEM images of SWCNTS (a, b) before and (c, d) after laser photoirradiation $\left(60 \mathrm{~mJ}\right.$ per pulse, $10 \mathrm{~Hz}$ ) for $2 \mathrm{~h}$ in deaerated $\mathrm{H}_{2} \mathrm{O}$ at $298 \mathrm{~K}$.

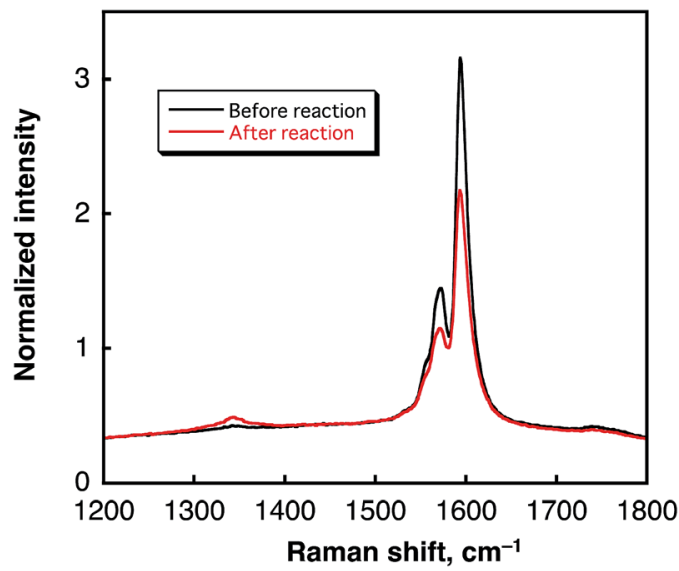

Fig. 9 Raman spectra of SWCNTs before laser irradiation (black line) and (b) SWCNTs obtained by laser light irradiation $(\lambda=532 \mathrm{~nm} ; 60 \mathrm{~mJ}$ per pulse; $10 \mathrm{~Hz})$ for $5 \mathrm{~h}$ in deaerated water $\left(0.80 \mathrm{mg} \mathrm{mL}^{-1}\right.$, red line).

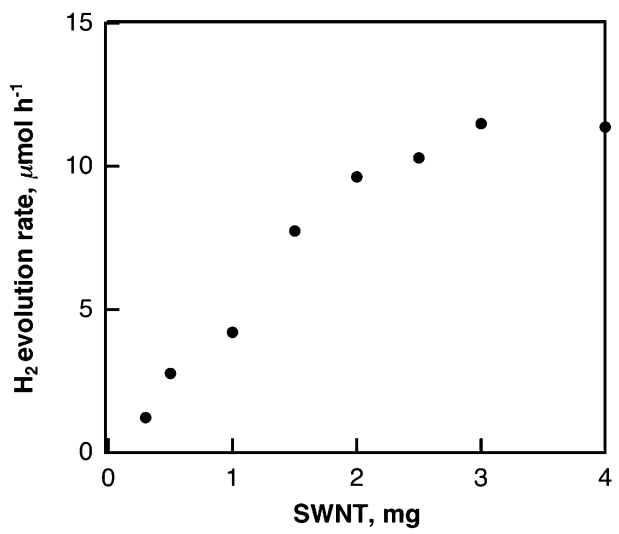

Fig. 10 Plot of rate of $\mathrm{H}_{2}$ evolution in deaerated $\mathrm{H}_{2} \mathrm{O}(2.5 \mathrm{~mL})$ containing various amounts of SWCNTs under laser irradiation at $532 \mathrm{~nm}$ (60 mJ per pulse; $10 \mathrm{~Hz}$ ) vs. amount of SWCNTs.

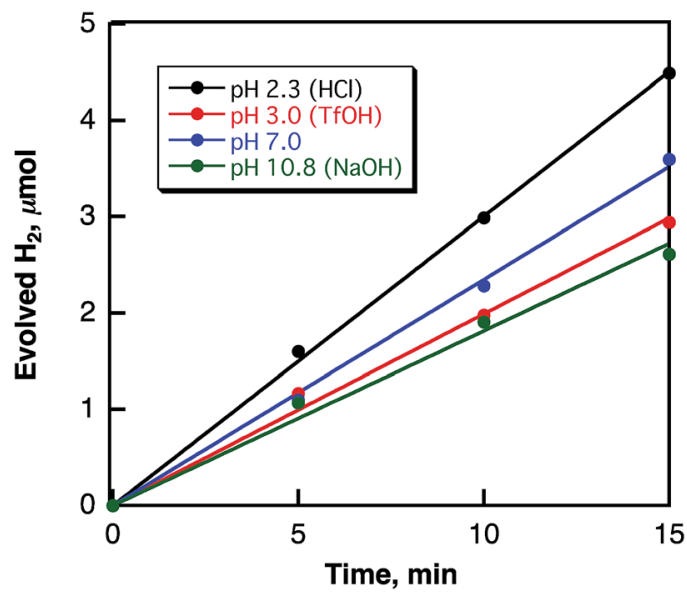

Fig. 11 Time courses of $\mathrm{H}_{2}$ evolution in deaerated $\mathrm{H}_{2} \mathrm{O}$ containing various amounts of SWCNTs $\left(0.80 \mathrm{mg} \mathrm{mL}^{-1}\right)$ under laser irradiation at $532 \mathrm{~nm}(60 \mathrm{~mJ}$ per pulse; $10 \mathrm{~Hz})$ at various $\mathrm{pHs}$. 


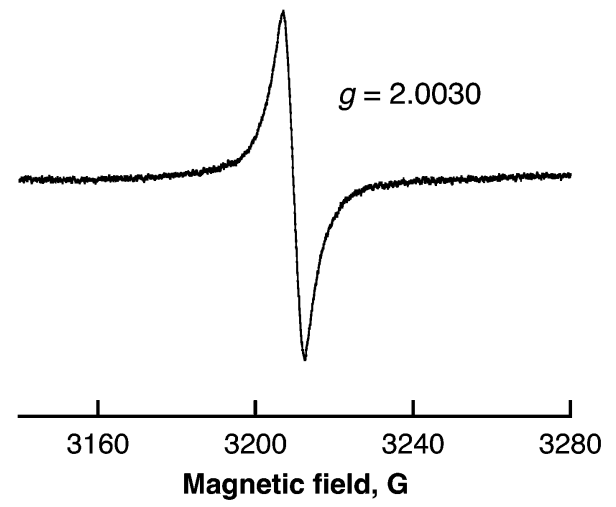

Fig. 12 ESR spectrum of frozen water containing SWCNTs $(0.80 \mathrm{mg}$ $\left.\mathrm{mL}^{-1}\right)$ after laser pulse irradiation at $532 \mathrm{~nm}(60 \mathrm{~mJ}$ per pulse; $10 \mathrm{~Hz})$ for $10 \mathrm{~min}$ at $77 \mathrm{~K}$.
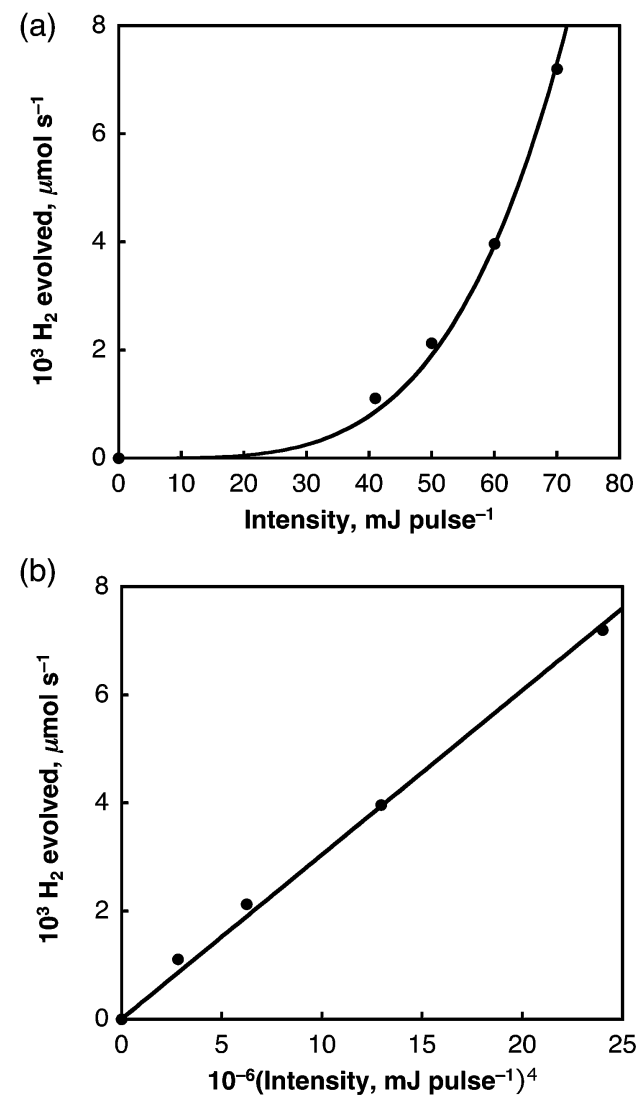

Fig. 13 (a) Plot of initial rate of $\mathrm{H}_{2}$ evolved in $\mathrm{H}_{2} \mathrm{O}$ vs. laser power intensity at $532 \mathrm{~nm}$; (b) plot of initial rate of $\mathrm{H}_{2}$ evolved vs. the fourth power of laser intensity.

produce $\mathrm{SWCNT}^{--}$and $\mathrm{C}_{6} \mathrm{H}_{6}$ with the rate constant $k_{\text {et2 }}$. The charge recombination from $\mathrm{SWCNT}^{\cdot-}$ to $\mathrm{SWCNT}^{\cdot+}$ also regenerates the SWCNT. The overall stoichiometry of the photocatalytic cycle in Scheme 1 agrees with eqn (1).

According to Scheme 1, the rate of hydrogen evolution is given by eqn (2). The rate of formation and decay of $\mathrm{C}_{6} \mathrm{H}_{6}{ }^{-}$is given by eqn (3).

\author{
$\mathrm{SWCNT} \stackrel{2 h v}{\rightarrow} \mathrm{SWCNT}^{* *}$ \\ $\mathrm{SWCNT}^{* *}+\mathrm{H}_{2} \mathrm{O} \rightarrow \mathrm{SWCNT}^{*+}+\mathrm{e}^{-}\left(\mathrm{H}_{2} \mathrm{O}\right)$ \\ $2 \mathrm{e}^{-}\left(\mathrm{H}_{2} \mathrm{O}\right) \rightarrow \mathrm{H}_{2}+2 \mathrm{OH}^{-}$ \\ $\mathrm{SWCNT}+\mathrm{OH}^{-} \rightarrow \mathrm{SWCNT}(\mathrm{OH})^{-}$
}

$\left.\mathrm{SWCNT}^{\cdot+}+\mathrm{SWCNT}(\mathrm{OH})^{-} \rightarrow \mathrm{SWCNT}+\mathrm{SWCNT}_{(\mathrm{OH}}\right)^{\bullet}$

$2 \mathrm{SWCNT}(\mathrm{OH})^{\bullet} \rightarrow \mathrm{SWCNT}+\mathrm{SWCNT}(\mathrm{OH})_{2}$

Scheme 3

$$
\begin{gathered}
\mathrm{d}\left[\mathrm{H}_{2}\right] / \mathrm{d} t=k_{\mathrm{H}}\left[\mathrm{C}_{6} \mathrm{H}_{6}{ }^{-{ }^{-}}\right]^{2} \\
\mathrm{~d}\left[\mathrm{C}_{6} \mathrm{H}_{6}{ }^{-}\right] / \mathrm{d} t= \\
k_{\mathrm{et} 1}\left[\mathrm{SWCNT}{ }^{* *}\right]-k_{\mathrm{H}}\left[\mathrm{C}_{6} \mathrm{H}_{6}{ }^{-{ }^{-}}\right]^{2} \\
-k_{\mathrm{et} 2}[\mathrm{SWCNT}]\left[\mathrm{C}_{6} \mathrm{H}_{6}{ }^{\left.-{ }^{-}\right]}\right.
\end{gathered}
$$

Assuming that $k_{\mathrm{et} 2}[\mathrm{SWCNT}]\left[\mathrm{C}_{6} \mathrm{H}_{6}{ }^{-{ }^{-}}\right] \gg k_{\mathrm{H}}\left[\mathrm{C}_{6} \mathrm{H}_{6}{ }^{-{ }^{-}}\right]^{2}$, the steadystate concentration of $\mathrm{C}_{6} \mathrm{H}_{6}{ }^{\cdot-}$ is given by eqn (4).

$$
\left[\mathrm{C}_{6} \mathrm{H}_{6}{ }^{--}\right]=k_{\mathrm{et} 1}\left[\mathrm{SWCNT}^{* *}\right] /\left(k_{\mathrm{et} 2}[\mathrm{SWCNT}]\right)
$$

From eqn (2) and (4), the rate of hydrogen evolution is rewritten by eqn (5).

$$
\mathrm{d}\left[\mathrm{H}_{2}\right] / \mathrm{d} t=k_{\mathrm{H}}\left[k_{\mathrm{et} 1}\left[\mathrm{SWCNT}^{* *}\right] /\left(k_{\mathrm{et} 2}[\mathrm{SWCNT}]\right)\right]^{2}
$$

Because the concentration of SWCNT** is proportional to the square of the laser intensity, the rate of hydrogen evolution is proportional to the fourth power of the laser intensity as observed in Fig. 4b. The observed deuterium kinetic isotope effect on the photocatalytic $\mathrm{H}_{2}$ evolution in Fig. 1 suggests that the $\mathrm{C}-\mathrm{H}$ bond cleavage of $\mathrm{C}_{6} \mathrm{H}_{6}{ }^{-}-\left(k_{\mathrm{H}}\right)$ is involved as the ratedetermining step in the radical coupling for $\mathrm{H}_{2}$ evolution in Scheme 1.

In Scheme $1, \mathrm{C}_{6} \mathrm{H}_{6}{ }^{-}$- produced by the electron transfer from $\mathrm{C}_{6} \mathrm{H}_{6}$ to SWCNT** dimerizes to afford $\mathrm{H}_{2}$ and $\left(\mathrm{C}_{6} \mathrm{H}_{5}\right)_{2}{ }^{2-}$, followed by rapid electron transfer from $\mathrm{C}_{6} \mathrm{H}_{6}$ to $\left(\mathrm{C}_{6} \mathrm{H}_{5}\right)_{2}{ }^{2-}$ to yield $\mathrm{C}_{6} \mathrm{H}_{6}{ }^{--}$and $\left(\mathrm{C}_{6} \mathrm{H}_{5}\right)_{2}{ }^{\cdot-}$. The overall reaction of $\mathrm{C}_{6} \mathrm{H}_{6}{ }^{--}$with $\mathrm{C}_{6} \mathrm{H}_{6}$ to yield $\mathrm{H}_{2}$ and $\left(\mathrm{C}_{6} \mathrm{H}_{5}\right)_{2}{ }^{\cdot-}$ is shown in Scheme 2 , where $\left(\mathrm{C}_{6} \mathrm{H}_{5}\right)_{2}{ }^{{ }^{-}-}$ can react further with $\mathrm{C}_{6} \mathrm{H}_{6}$ to produce the terphenyl radical anion $\left[\left(\mathrm{C}_{6} \mathrm{H}_{5}\left(\mathrm{C}_{6} \mathrm{H}_{4}\right) \mathrm{C}_{6} \mathrm{H}_{5}\right)^{\cdot-}\right]$ and $\mathrm{H}_{2}$. The same type of reaction continues and the overall reaction is given by eqn (6). Thus, once one mol of $\mathrm{C}_{6} \mathrm{H}_{6}{ }^{-}$is produced, $n$ moles of hydrogen can be produced from $n$ moles of benzene to form the radical anion of a benzene polymer $\left[\left(\mathrm{C}_{6} \mathrm{H}_{5}\left(\mathrm{C}_{6} \mathrm{H}_{4}\right)_{n-1} \mathrm{C}_{6} \mathrm{H}_{5}\right)^{\cdot-}\right]$, which may undergo charge recombination with $\mathrm{SWCNT}^{\cdot+}$ to regenerate the SWCNT.

According to Scheme 1, biphenyl is produced by the fourphoton process when the maximum value of the quantum yield is $25 \%$. However, the polymerisation of benzene induced by photo-generated $\mathrm{C}_{6} \mathrm{H}_{6}{ }^{\cdot-}$ in Scheme 2 gains a leverage effect to increase the quantum yield of $\mathrm{H}_{2}$ evolution above that expected from the four-photon process. Indeed, the highest quantum 
yield of $\mathrm{H}_{2}$ evolution was determined to be $130 \%$ at a laser power of $82 \mathrm{~mJ}$ per pulse under the conditions in Fig. 2a, where the photon number of the laser pulse was calibrated by ferrioxalate actinometry (see the experimental section in ESI $\dagger$ ). ${ }^{40}$

The efficiency of the photocatalytic $\mathrm{H}_{2}$ evolution is affected by substitution of the benzene ring with electron donating or withdrawing substituents (Table 1). The efficiency of photocatalytic $\mathrm{H}_{2}$ evolution is highest for benzene and lowest for 1,2dimethoxybenzene, because substitution on the benzene ring may retard the radical coupling with hydrogen and the electron donating substituents (methoxy group) may slow down electron transfer to the SWCNT** in Scheme 1.

Radical intermediates involved in the photocatalytic $\mathrm{H}_{2}$ evolution from benzene with SWCNTs were detected by ESR spectroscopy measured at $77 \mathrm{~K}$ as shown in Fig. 5. The observed ESR signal in the region of $g=2.0025$ can be assigned to radical anions derived from benzene, ${ }^{\mathbf{4 1}}$ which are overwrapped with SWCNT $^{*+} \cdot{ }^{42}$ The intensity of the ESR signal increased with increasing photoirradiation time because the stability of radical anions is expected to increase as the polymerisation of benzene in Scheme 2 proceeds.

\section{Laser-induced hydrogen evolution from water with SWCNTs}

Hydrogen evolution also occurred in deaerated $\mathrm{H}_{2} \mathrm{O}(2.5 \mathrm{~mL})$ containing dispersed metal-free SWCNTs $(2.0 \mathrm{mg})$ under NdYAG laser pulse irradiation $(\lambda=532 \mathrm{~nm} ; 600 \mathrm{~mW} ; 10 \mathrm{~Hz})$ as shown in Fig. 6. The amount of evolved $\mathrm{H}_{2}$ after $5 \mathrm{~h}$ reached 16.4 $\mu$ mol, which is $2.7 \times 10^{4}$ times larger than the amount of SWCNT $(0.6 \mathrm{nmol})$ calculated from the tube diameter and average length of SWCNTs with a zig-zag structure used in this study. When $\mathrm{H}_{2} \mathrm{O}$ was replaced by $\mathrm{D}_{2} \mathrm{O}$, the deuterated hydrogen molecules such as $\mathrm{D}_{2}$ and HD were also evolved (see Fig. S5 in ESI $\dagger$ ) and the KIE value was determined from the ratio of the $\mathrm{H}_{2}$ evolution in $\mathrm{H}_{2} \mathrm{O}$ vs. $\mathrm{D}_{2} \mathrm{O}$ (Fig. 7) to be 1.9, which is somewhat smaller than the value in benzene. These results indicate that the hydrogen source of evolved $\mathrm{H}_{2}$ is water.

In contrast to the case of benzene, no oxidized form of water (dioxygen or hydrogen peroxide) was produced after $\mathrm{H}_{2}$ evolution (see Fig. S3 in ESI $\dagger$ ). In such a case, SWCNTs may be oxidized, accompanied by the laser-induced $\mathrm{H}_{2}$ evolution. Comparison of the TEM images of SWCNTs before and after laser photoirradiation in $\mathrm{H}_{2} \mathrm{O}$ (Fig. 8) indicates that the tubular morphology remained after the $\mathrm{H}_{2}$ evolution by laser photoirradiation. Comparison of the Raman spectra of SWCNTs before and after laser photoirradiation of SWCNTs dispersed in deaerated $\mathrm{H}_{2} \mathrm{O}$ are shown in Fig. 9. The G-bands at 1590 and $1570 \mathrm{~cm}^{-1}$ decreased with the appearance of the D-band at 1340 $\mathrm{cm}^{-1}$. The increased $\mathrm{D} / \mathrm{G}$ ratio observed after the photoirradiation suggests that sidewall functionalisation of SWCNTs occurred..$^{\mathbf{4 3 4}}$ The IR spectra also suggest that SWCNTs were hydroxylated to exhibit O-H stretching vibrations at 3200-3600 $\mathrm{cm}^{-1}$ (Fig. S6 in ESI $\dagger$ ).

Comparison of the weight loss of SWCNTs before and after the laser irradiation in $\mathrm{H}_{2} \mathrm{O}$ observed in the TG measurements (Fig. S7 in ESI $\dagger$ ) also suggests that SWCNTs were hydroxylated. The number of $\mathrm{OH}$ groups of one SWCNT is estimated from the elemental analyses of SWCNTs before (C 96.81\% and $\mathrm{H} 0.19 \%)^{45}$ and after evolution of $16.4 \mu \mathrm{mol}$ of $\mathrm{H}_{2}$ (C $91.88 \%$ and $\mathrm{H} 0.60 \%$ ) to be 18000 . Thus, the $\mathrm{H}_{2}$ evolution is accompanied by the twoelectron oxidation of a SWCNT (attachment of two OH groups). The stoichiometry of the laser-induced $\mathrm{H}_{2}$ evolution with SWCNTs in $\mathrm{H}_{2} \mathrm{O}$ is given by eqn (7).

$$
2 \mathrm{H}_{2} \mathrm{O}+\mathrm{SWCNT} \stackrel{h v}{\rightarrow} \mathrm{H}_{2}+\operatorname{SWCNT}(\mathrm{OH})_{2}
$$

The laser-induced $\mathrm{H}_{2}$ evolution rate with SWCNTs in $\mathrm{H}_{2} \mathrm{O}$ increases with the increasing amount of SWCNTs to reach a constant value as shown in Fig. 10. This shows sharp contrast with the case of the laser-induced $\mathrm{H}_{2}$ evolution with SWCNTs in benzene, when the rate of $\mathrm{H}_{2}$ evolution was independent of the amount of SWCNTs as discussed above based on Scheme 1. The $\mathrm{pH}$ dependence of the $\mathrm{H}_{2}$ evolution rate was also examined as shown in Fig. 11, where the rate of $\mathrm{H}_{2}$ evolution is rather independent of $\mathrm{pH}$.

The overall stoichiometry agrees with that in eqn (7). The EPR spectrum exhibits a radical intermediate in the $\mathrm{H}_{2}$ evolution with SWCNTs from water as shown in Fig. 12. The EPR signal was clearly observed at $g=2.0030$ under laser irradiation at $77 \mathrm{~K}$ in frozen water containing SWCNTs. The $g$ value is larger than the signal at $g=2.0025$ observed in benzene (Fig. 5). Such a large $g$ value indicates the existence of $\operatorname{SWCNT}(\mathrm{OH})^{\circ}$ as a radical intermediate due to the spin-orbit coupling of oxygen in the laser-induced $\mathrm{H}_{2}$ evolution with SWCNTs in water.

As was the case for the laser-induced $\mathrm{H}_{2}$ evolution in benzene, the initial rates of laser-induced $\mathrm{H}_{2}$ evolution in $\mathrm{H}_{2} \mathrm{O}$ are proportional to the fourth power of laser intensity as shown in Fig. 13. This suggests that the doubly excited SWCNT (SWCNT**) and the subsequent bimolecular reaction are involved in the $\mathrm{H}_{2}$ evolution. In the case of $\mathrm{H}_{2} \mathrm{O}$, a solvated electron $\left(\mathrm{e}^{-}\left(\mathrm{H}_{2} \mathrm{O}\right)\right)$ may be produced by the reaction of SWCNT** with $\mathrm{H}_{2} \mathrm{O}$ as shown in Scheme 3, where the bimolecular reaction of $\mathrm{e}^{-}\left(\mathrm{H}_{2} \mathrm{O}\right)$ produces $\mathrm{H}_{2}$ and two equiv. of $\mathrm{OH}^{-}$ as indicated by the pulse radiolysis study of $\mathrm{H}_{2} \mathrm{O} .{ }^{46-49}$ The $\mathrm{OH}^{-}$ may be attached to a SWCNT to produce SWCNT $(\mathrm{OH})^{-}$, which is oxidized by the hole of SWCNT ${ }^{*+}$ to afford SWCNT(OH) ${ }^{\bullet}$, which may disproportionate to yield the dihydroxylated SWCNT [SWCNT $\left.(\mathrm{OH})_{2}\right]$, accompanied by the regeneration of the SWCNT.

\section{Conclusions}

In conclusion, SWCNTs have been demonstrated to act as efficient photocatalysts for $\mathrm{H}_{2}$ evolution from benzene derivatives under laser irradiation. The TON was over 1 million based on one nanotube. The rate of $\mathrm{H}_{2}$ evolution increased with increasing the laser intensity, exhibiting a fourth power dependence, because hydrogen was evolved via the radical coupling of radical anions derived from benzene as the ratedetermining step and a benzene radical anion was produced by electron transfer from the doubly excited state of a SWCNT to benzene, which requires two photons. The polymerisation of benzene induced by photogenerated $\mathrm{C}_{6} \mathrm{H}_{6}{ }^{-}$accompanied by 
$\mathrm{H}_{2}$ evolution gains a leverage effect to increase the quantum yield of $\mathrm{H}_{2}$ evolution to as high as $130 \%$, which is much larger than that expected from the four-photon process (25\%). Laserinduced $\mathrm{H}_{2}$ evolution also occurred with SWCNTs in $\mathrm{H}_{2} \mathrm{O}$, also exhibiting a fourth power dependence for the $\mathrm{H}_{2}$ evolution rate. In this case, $\mathrm{H}_{2}$ was evolved via the electron-transfer reduction of water by the doubly excited state of a SWCNT, and a SWCNT was oxidized to yield the dihydroxylated SWCNT. Metal-free laser-induced $\mathrm{H}_{2}$ evolution in aromatic compounds and $\mathrm{H}_{2} \mathrm{O}$ with SWCNTs found in this study paves a new way for efficient pinpoint hydrogen evolution, which may find various applications.

\section{Experimental section}

\section{Materials}

Chemicals were purchased from a commercial source and used without purification. SWCNTs (synthetic method: arc plasma jet, diameter: $1.4 \mathrm{~nm}$ approximate length: 1-5 $\mu \mathrm{m}$, percentage of carbon: >99\%) were obtained from Meijo Nano Carbon, Japan. The solution dispersed SWCNTs were prepared by ultrasonication ( $42 \mathrm{kHz}, 125 \mathrm{~W}$ ) for $5 \mathrm{~min}$. Benzene was of spectral grade, obtained commercially and used without further purification. Deuterated benzene $\left(\mathrm{C}_{6} \mathrm{D}_{6}, 99 \%\right)$ was obtained from Cambridge Isotope Laboratories, Inc., and was used as received. Benzonitrile was distilled over $\mathrm{P}_{2} \mathrm{O}_{5}$ in vacuo. ${ }^{50}$ Mesitylene, $p$ xylene, chlorobenzene and 1,4-dimethoxybenzene were obtained commercially and used as received. Potassium ferrioxalate used as an actinometer was prepared according to the literature and purified by recrystallisation from hot water. ${ }^{39} \mathrm{D}_{2}$ gas $(99.5 \%)$ was commercially obtained from Sumitomo Seika Chemicals Co., Ltd. Purification of water $(18.2 \mathrm{M} \Omega \mathrm{cm})$ was performed with a Milli-Q system (Millipore, Direct-Q 3 UV).

\section{Reaction procedure}

The photocatalytic hydrogen evolution was carried out by the following procedure. $\mathrm{C}_{6} \mathrm{H}_{6}, \mathrm{C}_{6} \mathrm{D}_{6}$ or benzene derivative solutions $\left(2.5 \mathrm{~cm}^{3}\right)$ containing SWCNTs $(0.15 \mathrm{mg})$ in a square quartz cuvette $(10 \mathrm{~mm}$ i.d.) sealed with a rubber septum was deaerated by bubbling with nitrogen through a stainless steel needle for 5 min. The solution was then irradiated with a Nd:YAG laser (LS2134UTF) at $\lambda=532 \mathrm{~nm}$ with the power of $50 \mathrm{~mJ}$ per pulse at room temperature. The gas in the headspace was analyzed using a Shimadzu GC-14B gas chromatograph (detector, TCD; column temperature, $50{ }^{\circ} \mathrm{C}$; column, active carbon with $60-80$ mesh particle size; carrier gas, $\mathrm{N}_{2}$ ) to quantify the evolved hydrogen. The reaction solution was analyzed by a Shimadzu GC-17A gas chromatograph and Shimadzu MS-QP5000 mass spectrometer to quantify the produced biphenyl, and HPLC [detector, UV at $\lambda=280 \mathrm{~nm}$ (SPD-10A, Shimadzu); column, Shim Pack VP-ODS; eluent, $\mathrm{CH}_{3} \mathrm{CN}$ : $0.40 \mathrm{~mL} \mathrm{~min}^{-1}$, water: 0.10 $\left.\mathrm{mL} \mathrm{min}^{-1}\right]$ to qualify the generated terphenyls. Hydrogen evolved in $\mathrm{C}_{6} \mathrm{D}_{6}$ after $2 \mathrm{~h}$ laser irradiation was detected using a Shimadzu GC-8A gas chromatograph [detector, TCD; column temperature, $77 \mathrm{~K}$ (liquid $\mathrm{N}_{2}$ ); column, Hydro Isopack $(2.0 \mathrm{~m}$, $4.0 \mathrm{~mm}$ i.d., GTR TEC Co., Ltd.); carrier gas, Ne] to analyze $\mathrm{H}_{2}$,
$\mathrm{HD}$ and $\mathrm{D}_{2}$ gases. In the case of measuring the laser intensity dependence, a benzene solution $\left(2.5 \mathrm{~cm}^{3}\right)$ containing SWCNTs $(0.15 \mathrm{mg})$ in a square quartz cuvette $(10 \mathrm{~mm}$ i.d.) sealed with a rubber septum was deaerated by bubbling with nitrogen through a stainless steel needle for $5 \mathrm{~min}$. The solution was then irradiated using a Nd:YAG laser (LS2134UTF) at $\lambda=532$ $\mathrm{nm}$ with the various laser intensities (18-82 $\mathrm{mJ}$ per pulse) at room temperature. The amount of hydrogen evolved was analyzed at 10, 20 and 30 min using a Shimadzu GC-14B gas chromatograph.

\section{Characterisation of SWCNTs as catalysts}

Transmission electron microscopy (TEM) images of SWCNTs before and after $2 \mathrm{~h}$ laser irradiation $(\lambda=532 \mathrm{~nm} ; 50 \mathrm{~mJ}$ per pulse; $10 \mathrm{~Hz}$ ) in a benzene solution were measured using a JEOL JEM 2100 operating at $200 \mathrm{kV}$. TG data were recorded on a SII TG/DTA 7200 instrument. SWCNTs, $(\sim 1 \mathrm{mg})$ before and after the reaction, were heated from $25{ }^{\circ} \mathrm{C}$ to $600{ }^{\circ} \mathrm{C}$ with a ramp rate of $2{ }^{\circ} \mathrm{C} \mathrm{min}^{-1}$. A certain amount of $\alpha-\mathrm{Al}_{2} \mathrm{O}_{3}$ was used as a reference for DTA measurements. Raman spectra were obtained using a JASCO NR-1800 with a $514.5 \mathrm{~nm}$ Ar laser. IR spectra were recorded on a JASCO FT/IR-6200, using KBr pellets.

\section{Quantum yield determinations}

A standard actinometer (potassium ferrioxalate) ${ }^{39}$ was used for the quantum yield determination of hydrogen evolution from benzene with SWCNTs. A square quartz cuvette (10 mm i.d.) containing a benzene solution $\left(2.5 \mathrm{~cm}^{3}\right)$ of SWCNTs $(0.15 \mathrm{mg})$ was irradiated using a Nd:YAG laser (LS2134UTF) at $\lambda=532 \mathrm{~nm}$ with the various laser intensities (18-82 $\mathrm{mJ}$ per pulse). Under the conditions of actinometry experiments, SWCNTs absorbed essentially $100 \%$ of the incident light of $\lambda=532 \mathrm{~nm}$. The light intensity of the laser light of $\lambda=532 \mathrm{~nm}$ was determined as 6.5 $\times 10^{-9}$ einstein $\mathrm{s}^{-1}$ at $8.0 \mathrm{~mJ}$ per pulse. The photochemical reaction was monitored using a Shimadzu GC-14B gas chromatograph. The quantum yields were determined from the amount of hydrogen evolved.

\section{EPR measurements}

The EPR spectra were measured on a JEOL X-band EPR spectrometer (JES-ME-LX) using a quartz EPR tube containing SWCNTs $(24 \mu \mathrm{g})$ dispersed in deaerated benzene $\left(0.20 \mathrm{~cm}^{3}\right)$ by laser irradiation $(\lambda=532 \mathrm{~nm} ; 40 \mathrm{~mJ}$ per pulse; $10 \mathrm{~Hz}$ ) for $10 \mathrm{~min}$ at $77 \mathrm{~K}$. The internal diameter of the EPR tube is $4.5 \mathrm{~mm}$, which is small enough to fill the EPR cavity but large enough to obtain good signal-to-noise ratios during the EPR measurements. The amplitude of modulation was chosen to optimize the resolution and the signal-to-noise $(S / N)$ ratio of the observed spectra. The $g$ values were calibrated with an $\mathrm{Mn}^{2+}$ marker.

\section{Acknowledgements}

This work was supported by Grants-in-Aid (nos 26620154 and 26288037 to K.O. and nos 24350069 and 25600025 to Y.Y.) from the Ministry of Education, Culture, Sports, Science and Technology (MEXT) and an ALCA project from JST, Japan (to S.F.). 
We acknowledge Research Centre for Ultra-Precision Science \& Technology in Osaka University for TEM measurements.

\section{Notes and references}

1 (a) L. Dai, Acc. Chem. Res., 2013, 46, 31; (b) L. Dai, D. W. Chang, J.-B. Baek and W. Lu, Small, 2012, 8, 1130; (c)

T. Chen and L. Dai, Mater. Today, 2013, 16, 272.

2 (a) P. V. Kamat and G. C. Schatz, J. Phys. Chem. C, 2009, 113, 15437; (b) P. V. Kamat, J. Phys. Chem. Lett., 2011, 2, 242.

3 U. Sahaym and N. M. Grant, J. Mater. Sci., 2008, 43, 5395.

4 (a) A. Arico, Nat. Mater., 2005, 4, 366; (b) D. R. Rolison, J. W. Long, J. C. Lytle, A. E. Fischer, C. P. Rhodes, T. M. McEvoy, A. M. Bourg and M. E. Lubers, Chem. Soc. Rev., 2009, 38, 226.

5 (a) M. Z. Jacobson, Energy Environ. Sci., 2009, 2, 148; (b) R. M. Dell and D. A. J. Rand, J. Power Sources, 2001, 100, 2.

6 N. Keller, N. I. Maksimova, V. V. Roddatis, M. Schur, G. Mestl, Y. V. Butenko, V. L. Kuznetsov and R. Schlögl, Angew. Chem., Int. Ed., 2002, 41, 1885.

7 J. Zhang, D. Su, A. Zhang, D. Wang, R. Schlögl and C. Hébert, Angew. Chem., Int. Ed., 2007, 46, 7319.

8 (a) N. Zhang, Y. Zhang and Y.-J. Xu, Nanoscale, 2012, 4, 5792; (b) N. Zhang, Y. Zhang, M.-Q. Yang, Z.-R. Tang and Y.-J. Xu, J. Catal., 2013, 299, 210; (c) Y. Zhang, Z.-R. Tang, X. Fu and Y.-J. Xu, ACS Nano, 2011, 5, 7426.

9 F. Goettmann, A. Fischer, M. Antonietti and A. Thomas, Angew. Chem., Int. Ed., 2006, 45, 4467.

10 J. J. Díaz, L. M. C. Suárez and J. L. Figueiredo, Appl. Catal., A, 2006, 311, 51.

11 (a) S. Iijima and T. Ichihashi, Nature, 1993, 363, 603; (b) K. Hata, D. N. Futaba, K. Mizuno, T. Namai, M. Yumura and S. Iijima, Science, 2004, 306, 1362.

12 (a) Y. Chen and J. Zhang, Acc. Chem. Res., 2014, 47, 2273; (b) M. F. L. De Volder, S. H. Tawfick, R. H. Baughman and A. J. Hart, Science, 2013, 339, 535; (c) L. Kavan and L. Dunsch, ChemPhysChem, 2011, 12, 47.

13 D. M. Guldi, G. M. A. Rahman, F. Zerbetto and M. Prato, Acc. Chem. Res., 2005, 38, 871.

14 A. C. Dillon, K. M. Jones, T. A. Bekkedahl, C. H. Kiang, D. S. Bethune and M. J. Heben, Nature, 1997, 386, 377.

15 (a) C. N. R. Rao and A. Govindaraj, Acc. Chem. Res., 2002, 35, 998; (b) C. N. R. Rao and A. Govindaraj, RSC Nanosci. Nanotechnol., 2011, 18, 1; (c) C. J. Shearer, A. Cherevan and D. Eder, Adv. Mater., 2014, 26, 2295; (d) Y. Lin, J. Ren and X. Qu, Acc. Chem. Res., 2014, 47, 1097.

16 (a) B. Mu, J. Zhang, T. P. McNicholas, N. F. Reuel, S. Kruss and M. S. Strano, Acc. Chem. Res., 2014, 47, 979; (b) D. A. Heller, H. Jin, B. M. Martinez, D. Patel, B. M. Miller, T.-K. Yeung, P. V. Jena, C. Hoebartner, T. Ha, S. K. Silverman and M. S. Strano, Nat. Nanotechnol., 2009, 4, 114.

17 (a) Y. Miyauchi, J. Mater. Chem. C, 2013, 1, 6499; (b) S. Schafer, N. M. B. Cogan and T. D. Krauss, Nano Lett., 2014, 14, 3138.

18 (a) J. Gao, J. Zhong, L. Bai, J. Liu, G. Zhao and X. Sun, Sci. Rep., 2014, 4, 3606; (b) M. Lefévre, E. Proietti, F. Jaouen and J. Dodelet, Science, 2009, 324, 71; (c) D. H. Lee, W. J. Lee, S. O. Kim and Y. H. Kim, Phys. Rev. Lett., 2011, 106, 175502.

19 D. R. Rolision, Science, 2003, 299, 1698.

20 (a) T. Iwasita, Electrochim. Acta, 2002, 47, 3663; (b) E. A. Batista, G. R. P. Malpass, A. J. Motheo and T. Iwasita, Electrochem. Commun., 2003, 5, 843.

21 A. Züttel, A. Borgschulte and L. Schlapbach, Hydrogen as a Future Energy Carrier, Wiley-VCH, Weinheim, Germany, 2008.

22 S. Fukuzumi, Eur. J. Inorg. Chem., 2008, 1351.

23 (a) Q. Xiang, J. Yu and M. Jaroniec, J. Am. Chem. Soc., 2012, 134, 6575; (b) Q. Xiang, J. Yu and M. Jaroniec, Nanoscale, 2011, 3, 3670; (c) Q. Xiang, J. Yu and M. Jaroniec, J. Phys. Chem. C, 2011, 115, 7355.

24 A. Iwase, Y. H. Ng, Y. Ishiguro, A. Kudo and R. Amal, J. Am. Chem. Soc., 2011, 133, 11054.

25 Q. Li, B. Guo, J. Yu, J. Ran, B. Zhang, H. Yan and J. R. Gong, J. Am. Chem. Soc., 2011, 133, 10878.

26 (a) W. Fan, Q. Lai, Q. Zhang and Y. Wang, J. Phys. Chem. C, 2011, 115, 10694; (b) A. Mukherji, B. Seger, G. Q. Lu and L. Wang, ACS Nano, 2011, 5, 3483-3492.

27 (a) M. G. Walter, E. L. Warren, J. R. McKone, S. W. Boettcher, Q. Mi, E. A. Santori and N. S. Lewis, Chem. Rev., 2010, 110, 6446; (b) X. Chen, S. Shen, L. Guo and S. S. Mao, Chem. Rev., 2010, 110, 6503.

28 (a) K. Maeda and K. Domen, J. Phys. Chem. Lett., 2010, 1, 2655; (b) K. Maeda, ACS Catal., 2013, 3, 1486; (c) A. Kudo and Y. Miseki, Chem. Soc. Rev., 2009, 38, 253.

29 (a) J.-M. Lehn and J.-P. Sauvage, Nouv. J. Chim., 1977, 1, 449; (b) K. Kalyanasundaram, Coord. Chem. Rev., 1982, 46, 159; (c) J. R. Darwent, P. Douglas, A. Harriman, G. Porter and M.-C. Richoux, Coord. Chem. Rev., 1982, 44, 83; (d) J. Kiwi and M. Grätzel, J. Am. Chem. Soc., 1979, 101, 7214; (e) M. Grätzel, Acc. Chem. Res., 1981, 14, 376.

30 (a) D.-L. Jiang, C.-K. Choi, K. Honda, W.-S. Li, T. Yuzawa and T. Aida, J. Am. Chem. Soc., 2004, 126, 12084; (b) Y. Amao, Y. Tomonou and I. Okura, Sol. Energy Mater. Sol. Cells, 2003, 79, 103.

31 (a) M. S. Oskoui, M. Khatamian, M. Haghighi and A. Yavari, RSC Adv., 2014, 4, 19569; (b) F. Chen, J. Zai, M. Xu and X. Qian, J. Mater. Chem. A, 2013, 1, 4316; (c) F. Dai, J. Zai, R. Yi, M. L. Gordin, H. Sohn, S. Chen and D. Wang, Nat. Commun., 2014, 5, 4605.

32 (a) J. Li, S. K. Cushing, P. Zheng, T. Senty, F. Meng, A. D. Bristow, A. Manivannan and N. Wu, J. Am. Chem. Soc., 2014, 136, 8438; (b) Q. Xiang, J. Yu and M. Jaroniec, J. Am. Chem. Soc., 2012, 134, 6575; (c) F. Meng, J. Li, S. K. Cushing, M. Zhi and N. Wu, J. Am. Chem. Soc., 2013, 135, 10286; (d) C. Yang, Z. Wang, T. Lin, H. Yin, X. Lu, D. Wan, T. Xu, C. Zheng, J. Lin, F. Huang, X. Xie and M. Jiang, J. Am. Chem. Soc., 2013, 135, 17831.

33 (a) S. R. Lingampalli and C. N. R. Rao, J. Mater. Chem. A, 2014, 2, 7702; (b) J. Wang, Z. Guan, J. Huang, Q. Li and J. Yang, J. Mater. Chem. A, 2014, 2, 7960; (c) S. Wang, L. Zhao, L. Bai, J. Yan, Q. Jiang and J. Lian, J. Mater. Chem. 
A, 2014, 2, 7439; (d) J. Yang and H. S. Shin, J. Mater. Chem. A, 2014, 2, 5979.

34 (a) S. Fukuzumi and Y. Yamada, J. Mater. Chem., 2012, 22, 24284; (b) S. Fukuzumi and T. Suenobu, Dalton Trans., 2013, 18; (c) S. Fukuzumi, D. Hong and Y. Yamada, J. Phys. Chem. Lett., 2013, 4, 3458; (d) S. Fukuzumi and Y. Yamada, ChemSusChem, 2013, 6, 1834; (e) Y. Yamada, S. Shikano and S. Fukuzumi, J. Phys. Chem. C, 2013, 117, 13143.

35 (a) H. Kotani, T. Ono, K. Ohkubo and S. Fukuzumi, Phys. Chem. Chem. Phys., 2007, 9, 1487; (b) H. Kotani, R. Hanazaki, K. Ohkubo, Y. Yamada and S. Fukuzumi, Chem.-Eur. J., 2011, 17, 2777; (c) Y. Yamada, T. Miyahigashi, H. Kotani, K. Ohkubo and S. Fukuzumi, J. Am. Chem. Soc., 2011, 133, 16136; (d) Y. Yamada, T. Miyahigashi, H. Kotani, K. Ohkubo and S. Fukuzumi, Energy Environ. Sci., 2012, 5, 6111.

36 Metal-free $\mathrm{H}_{2}$ evolution from polymeric carbon nitride has been reported. See: X. Wang, K. Maeda, A. Thomas, K. Takanabe, G. Xin, J. M. Carlsson, K. Domen and M. Antonietti, Nat. Mater., 2009, 8, 76.

37 Number of carbon atoms on SWCNT was estimated by diameter and length of SWCNT $(\phi=1.4 \mathrm{~nm} ; l=1-5 \mu \mathrm{m})$ and carbon-carbon bond length $(0.14 \mathrm{~nm})$ to be $2.7 \times 10^{5}$ carbons per SWCNT. Number of moles of SWCNT in solution is calculated by $0.15(\mathrm{mg}) /\left(12 \times 2.7 \times 10^{5}\right)$ to be $4.5 \times 10^{-8} \mathrm{mmol}$.

38 (a) M. G. Stevens, K. M. Sellers, S. Subramoney and H. C. Foley, Chem. Commun., 1998, 2679; (b) J. Mortensen and J. Heinze, Angew. Chem., Int. Ed. Engl., 1984, 23, 84.

39 K. Meerholz and J. Heinze, J. Am. Chem. Soc., 1989, 111, 2325.
40 (a) C. G. Hatchard and C. A. Parker, Proc. R. Soc. London, Ser. $A$, 1956, 235, 518; (b) J. G. Calvert and J. N. Pitts, Photochemistry, Wiley, New York, 1966, p. 783.

41 (a) R. G. Kooser, W. V. Volland and J. H. Freed, J. Chem. Phys., 1969, 50, 5243; (b) B. G. Segal, M. Kaplan and G. K. Frankel, J. Chem. Phys., 1965, 43, 4191.

42 Aromatic carbon centered radical ion was observed close to $g$ $=2.0023$ which is a value of free spin. J. B. Jones and L. S. Singer, Carbon, 1982, 20, 379.

43 (a) J. Chen, M. A. Hamon, H. Hu, Y. Chen, A. M. Rao, P. C. Eklund and R. C. Haddon, Science, 1998, 282, 95; (b) H. Hu, B. Zhao, M. A. Hamon, K. Kamaras, M. E. Itkis and R. C. Haddon, J. Am. Chem. Soc., 2003, 125, 14893.

44 Y. Maeda, J. Higo, Y. Amagai, J. Matsui, K. Ohkubo, Y. Yoshigoe, M. Hashimoto, K. Eguchi, M. Yamada, T. Hasegawa, Y. Sato, J. Zhou, J. Lu, T. Miyashita, S. Fukuzumi, T. Murakami, K. Tohji, S. Nagase and T. Akasaka, J. Am. Chem. Soc., 2013, 135, 6356.

$450.19 \%$ of hydrogen may be produced from adsorbed water on SWCNTs surface, accompanied by the hydroxylation of SWCNTs.

46 L. Turi and P. J. Rossky, Chem. Rev., 2012, 112, 5641.

47 Y. Muroya, M. Lin, V. de Waele, Y. Hatano, Y. Katsumura and M. Mostafavi, J. Phys. Chem. Lett., 2010, 1, 331.

48 B. Pastina and J. A. LaVerne, J. Phys. Chem. A, 1999, 103, 209. 49 C. Fourdrin, H. Aarrachi, C. Latrille, S. Esnouf, F. Bergaya and S. Le Caër, Environ. Sci. Technol., 2013, 47, 9530.

50 W. L. F. Armarego and C. L. L. Chai, in Purificationof Laboratory Chemicals, Butterworth-Heinemann, Oxford, 6th edn, 2009. 